\title{
Influence of thermal zoning and electric radiator control on the energy flexibility potential of Norwegian detached houses
}

\author{
Thea Johnsen ${ }^{1, *}$, Katrine Taksdal ${ }^{1}$, John Clau $\beta^{1}$, Xingji Y $u^{l}$ and Laurent Georges ${ }^{1}$ \\ ${ }^{1}$ Energy and Process Engineering Department, Norwegian University of Science and Technology (NTNU)
}

\begin{abstract}
Energy flexibility of buildings can be used to reduce energy use and costs, peak power, $\mathrm{CO}_{2 \mathrm{eq}}$ emissions or to increase self-consumption of on-site electricity generation. Thermal mass activation proved to have a large potential for energy flexible operation. The indoor temperature is then allowed to fluctuate between a minimum and maximum value. Many studies investigating thermal mass activation consider electric radiators. Nevertheless, these studies most often assume that radiators modulate their emitted power, while, in reality, they are typically operated using thermostat (on-off) control. Firstly, this article aims at comparing the energy flexibility potential of thermostat and P-controls for Norwegian detached houses using detailed dynamic simulations (here IDA ICE). It is evaluated whether the thermostat converges to a P-control for a large number of identical buildings. As the buildings are getting better insulated, the impact of internal heat gains (IHG) becomes increasingly important. Therefore, the influence of different IHG profiles has been evaluated in the context of energy flexibility. Secondly, most studies about energy flexibility consider a single indoor temperature. This is questionable in residential buildings where people may want different temperature zones. This is critical in Norway where many occupants want cold bedrooms $\left(\sim 16^{\circ} \mathrm{C}\right)$ during winter time and open bedroom windows for this purpose. This article answers to these questions for two different building insulation levels and two construction modes (heavy and lightweight).
\end{abstract}

\section{Introduction}

Energy consumption needs to be more flexible. Firstly, the use of power demanding electric appliances is increasing which means that consumers are demanding more power from the distribution grid than before and often at the same time. The power grid is dimensioned to accommodate the highest possible load that can occur. Since the consumption of electricity varies significantly over hours, days and years, the grid will only experience this dimensioning load for short periods [1]. During an average weekday, the electricity consumption in Norwegian residential buildings peaks between 07:00 and 10:00 and between 16:00 and 21:00 [2]. Secondly, to make the transition to a sustainable energy system, more of the electricity must be produced from renewable energy sources. However, an increasing production from intermittent energy sources such as solar and wind may have serious adverse effects on the stability of the electricity grid. Therefore, it will become increasingly important to shift from a system based on generation-ondemand to a system where the energy use is flexible and controlled according to grid requirements or intermittent energy production.

In the recent years, there has been an increasing focus on energy flexibility on the demand side. Demand side management (DSM) adapts the consumption according to the needs of the surrounding electricity grid [3]. When the electricity use for heating and cooling is considered for
DSM, a thermal storage is necessary [4]. For buildings, DSM can be achieved in several ways, for example using heat storage in hot-water tanks or in the thermal mass and by shifting the use of plug loads in time [5]. Storage in the building structure, i.e. the building thermal mass, has been identified as a promising and cost-effective way for buildings to offer flexibility $[6,7]$. The available storage capacity in the building structure is not only dependent on the material properties but also on the geometry of the building, the distribution of thermal mass inside the building and the interaction with the heating system. In addition, the performance of structural thermal storage will vary with time, as weather conditions and occupant behavior affect the available storage capacity [8].

To activate the thermal mass of the building, a suitable control strategy is necessary. Rule Based Control (RBC) is a common control approach for energy systems in buildings. Even though simpler than Model Predictive Control (MPC), RBC can still be used to deploy the building energy flexibility [4]. For instance, RBC has been investigated for Norwegian residential buildings using either time-scheduled or day-ahead electricity prices to control the set-point indoor temperature $[9,10]$.

Key performance indicators (KPIs) can be used to evaluate the performance of a system with respect to a specific desired result. A KPI is a parameter (or value) that provides simplified information about a complex system, to show the general state or trend [11]. For instance, KPIs

\footnotetext{
* Corresponding author: thea.john@stud.ntnu.no
} 
are necessary to quantify the energy flexibility generated by different control strategies. Typical KPIs of building energy flexibility can describe physical features of the building, such as the storage capacity, or quantify the magnitude of the building's response to external signals, e.g. the electricity price [4].

Simplifications of modelling the occupant behavior is a main reason for the gap between the predicted and actual energy performance of a building. For buildings with better insulation levels, internal heat gains (IHG) have an increasing contribution to the space-heating demand [12]. It is common practice in the building industry to dimension the power of the space-heating system without accounting for IHGs. This often leads to oversizing of the space-heating system in highly-insulated buildings. In addition, it is important to use realistic IHG profiles in energy simulations to get reliable predictions of the actual energy performance. For instance, a bottom-up stochastic model to generate realistic electricity load profiles can be used to create realistic IHG profiles [13].

Several studies have identified occupant dissatisfaction with too high bedroom temperatures in Norwegian highly-insulated buildings during winter time. Low temperature in bedrooms is difficult to achieve without window opening which eventually leads to a significant increase of the space-heating needs. This is especially true when there is a desire for higher temperatures in the rest of the building [14-18]. One key characteristic of DSM is user acceptability, i.e. the occupant's willingness to accept that the building is controlled depending on the needs of the electricity grid [3]. For example, a compromise could be a cheaper electricity bill at the sacrifice of thermal comfort (within certain limits). Storing heat using the building thermal mass typically leads to relatively high indoor temperatures which can prevent reaching cold temperatures in bedrooms. Only a limited number of studies investigated the effect of thermal zoning on building energy flexibility. Different temperature set-points (TSP) are defined for so-called day-zones and night-zones, with the TSP for the day zone is slightly higher than the TSP of the night zone $[6,19$, 20]. However, most studies assume a single temperature for the entire building.

The Norwegian building stock is dominated by singlefamily houses (SFH). The interest in high-performance buildings is rapidly increasing but they still represent a small fraction of the building stock. In 2013, only $31 \%$ of the inhabited building stock were built after 1980 [21]. In Norwegian residential buildings, the most common spaceheating system is electric radiators, however, the number of heat pump installations is increasing [21, 22]. According to electric radiator manufacturers, the most common control of these radiators is thermostatic control (meaning that the radiator is operated at full power between a start and stop temperature). Nevertheless, the studies on energy flexibility are usually done assuming a continuous power modulation. This can for example be a proportional (P) controller or a proportional-integral (PI) controller.

The objectives of this study is to identify the flexibility potential of Norwegian detached houses heated by electric radiators. More specifically, this energy flexibility potential is compared between a thermostatic and a proportional control of the radiators. Furthermore, the influence of the thermal mass activation on internal thermal zoning is investigated as well as the impact of such a zoning on the flexibility potential. These questions are investigated using detailed dynamic simulations in IDA ICE. A detached house controlled with two simple $\mathrm{RBC}$ strategies for heating is simulated. Since IHGs are expected to have an influence on the building thermal dynamics, different scenarios of IHG profiles are evaluated. This includes fixed IHG profiles defined from standards but also stochastic IHG profiles. Stochastic IHG profiles enable to investigate whether the thermostat control converges to a P-control when energy flexibility is evaluated for a large number of identical buildings, at a so-called aggregated level.

\section{Methodology}

\subsection{Definition of the case building}

A two-storey detached house with a heated floor area of $160 \mathrm{~m}^{2}$ located in Oslo is used as a case study. An illustration of the building geometry from IDA ICE is shown in Fig. 1.

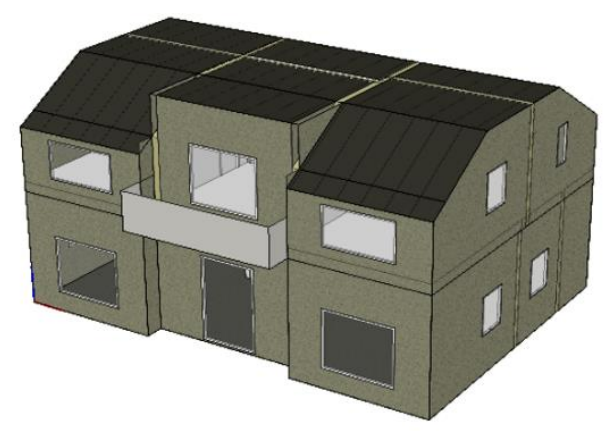

Fig. 1. 3D geometry of the building model implemented in IDA ICE (showing the southwest façade).

Two different construction modes are investigated, one lightweight timber construction (LCM) and one heavy masonry construction (HCM). The heat storage capacity and the average $U$-values of the internal structures for the two construction modes are listed in Table 1.

Table 1. Heat storage capacity and average U-value of the internal walls and floors for the lightweight construction mode (LCM) and the heavy construction mode (HCM).

\begin{tabular}{lccc}
\hline $\begin{array}{l}\text { Construction } \\
\text { mode }\end{array}$ & $\begin{array}{c}\text { Heat storage } \\
\text { capacity } \\
{[\mathbf{M J} / \mathbf{K}]}\end{array}$ & $\begin{array}{c}\mathbf{U}_{\text {int.wall }} \\
{\left[\mathbf{W} / \mathbf{m}^{2} \mathbf{K}\right]}\end{array}$ & $\begin{array}{c}\mathbf{U}_{\text {int.floor }} \\
{\left[\mathbf{W} / \mathbf{m}^{2} \mathbf{K}\right]}\end{array}$ \\
\hline $\mathrm{HCM}$ & 86 & 2.84 & 1.60 \\
$\mathrm{LCM}$ & 14 & 0.25 & 0.21 \\
\hline
\end{tabular}

Furthermore, two levels of insulation are investigated, one corresponding to the Norwegian passive house $(\mathrm{PH})$ standard and the other is set in accordance with the example building of the TABULA project in the age segment 1981-1990 (TB building) [23, 24]. This results in a total of four investigated building types; passive house 
standard with heavy construction (PHH) and lightweight construction (PHL), and an insulation level typical for a building built in the 1980s with heavy construction (TBH) and lightweight construction (TBL). The building envelope specifications for the $\mathrm{PH}$ and $\mathrm{TB}$ insulation levels are listed in Table 2. The PH buildings are modeled with a balanced mechanical ventilation system with heat recovery and an air temperature of $20^{\circ} \mathrm{C}$ for the supply ventilation air. The ventilation airflow rates are in accordance with the Norwegian building code [25]. Natural ventilation is usually applied to old buildings. For the sake of simplicity the TB buildings are modelled with a balanced mechanical ventilation without heat recovery.

Table 2. U-values for external constructions $\left(\mathrm{W} / \mathrm{m}^{2} \mathrm{~K}\right)$, infiltration rate $\left(n_{50}\right)$, normalized thermal bridge factor ( $\left.\Psi^{\prime \prime}\right)$ and heat recovery effectiveness $\left(\eta_{H R}\right)$ for the PH and TB insulation levels.

\begin{tabular}{lcc}
\hline Construction element & PH & TB \\
\hline $\mathrm{U}_{\text {roof }}\left[\mathrm{W} / \mathrm{m}^{2} \mathrm{~K}\right]$ & 0.10 & 0.36 \\
$\mathrm{U}_{\text {ext.wall }}\left[\mathrm{W} / \mathrm{m}^{2} \mathrm{~K}\right]$ & 0.10 & 0.32 \\
$\mathrm{U}_{\text {ext.floor }}\left[\mathrm{W} / \mathrm{m}^{2} \mathrm{~K}\right]$ & 0.09 & 0.20 \\
$\mathrm{U}_{\text {windows }}\left[\mathrm{W} / \mathrm{m}^{2} \mathrm{~K}\right]$ & 0.8 & 2.80 \\
$\mathrm{n}_{50}\left[\mathrm{~h}^{-1}\right]$ & 0.6 & 4 \\
$\Psi{ }^{\prime}\left[\mathrm{W} / \mathrm{m}^{2} \mathrm{~K}\right]$ & 0.03 & 0.05 \\
$\eta_{\text {HR }}[\%]$ & 85 & 0 \\
\hline
\end{tabular}

The space-heating system consists of electric radiators in every room except for the two bathrooms and the laundry room which are equipped with floor heating. The nominal space-heating power of each room is evaluated using IDA ICE simulations with ideal heaters, no IHG and a constant design outdoor temperature (DOT) of Oslo (i.e. $-19.8^{\circ} \mathrm{C}$ ). The dimensioning of the radiator is done according to the current practice: the nominal power of the radiators and floor heating equals the nominal power of the respective room they are located in. The radiator control has a deadband $(\Delta)$ and P-band of $1{ }^{\circ} \mathrm{C}$. The thermostat control starts at TSP $-\Delta / 2$ and stops at TSP $+\Delta / 2$.

\subsection{Rule-based control strategies}

To evaluate the energy flexibility potential, two different RBC strategies are applied: an off-peak hour control strategy (OPCS) and a spot price control strategy (SPCS). Both adjust the TSP of the space-heating system.

The OPCS aims at reducing the electricity use for spaceheating during peak hours. This objective is critical for Norway as the distribution grid is expected to face bottlenecks in the near future [26]. Peak hours are based on the average electricity consumption of Norwegian residential buildings on a weekday. Based on this daily profile, peak hours for electricity consumption are defined between 07:00 and 09:00 as well as between 17:00 and 19:00 [2]. With OPCS, the TSP is $21{ }^{\circ} \mathrm{C}$ in all rooms. Nevertheless, this temperature is reduced by $2 \mathrm{~K}$ in the defined peak hours while it is increased by $2 \mathrm{~K}$ one hour before peak hours to store energy in the thermal mass.
The SPCS aims at reducing energy costs for spaceheating. It is based on the day-ahead hourly spot price for electricity, retrieved from NordPool [27]. The TSP is here controlled using two thresholds for the electricity price. The low and high thresholds are set to the minimum spot price plus $25 \%$ and $75 \%$ of the difference between the minimum and maximum day-ahead spot prices, respectively. Therefore, thresholds are updated every day. These two thresholds define periods of low, medium and high electricity prices. The SPCS decreases the TSP by $2 \mathrm{~K}$ in high-price periods, keeps the TSP at $21^{\circ} \mathrm{C}$ in medium-price periods and increases the TSP by $2 \mathrm{~K}$ in low price periods. Since the nighttime is characterized with a low electricity demand, the spot price is relatively low. The SPCS would initially exploit this low price to increase the TSP. This is expected to lead to a higher energy consumption and cost, as concluded in a previous study [9]. Therefore, the SPCS only operates between 06:00 and 23:00. Otherwise it is overruled to $21^{\circ} \mathrm{C}$.

\subsection{Internal heat gain profiles}

Four different IHG profiles are investigated. Two are based on Norwegian standards and are uniform in space. Nevertheless, one of these profiles is static (NS) and the other one is distributed in time with a fixed daily profile (TS). The two other IHG profiles are stochastic, with variations from day to day and between the seasons. The magnitude of these stochastic profiles is the same, but one profile contains IHGs distributed in time $\left(\mathrm{SM}_{t}\right)$ while the second has IHGs varying in both time and space $\left(\mathrm{SM}_{\mathrm{ts}}\right)$.

The annual profile for lighting and electric appliances is generated using the bottom-up model developed by Richardson et. al. [13] which has been adjusted to Norwegian households by Rangøy [28]. However, there is currently no stochastic occupancy model compatible with the available Norwegian statistical data. Therefore, a fixed occupancy profile with an hourly resolution was created artificially.

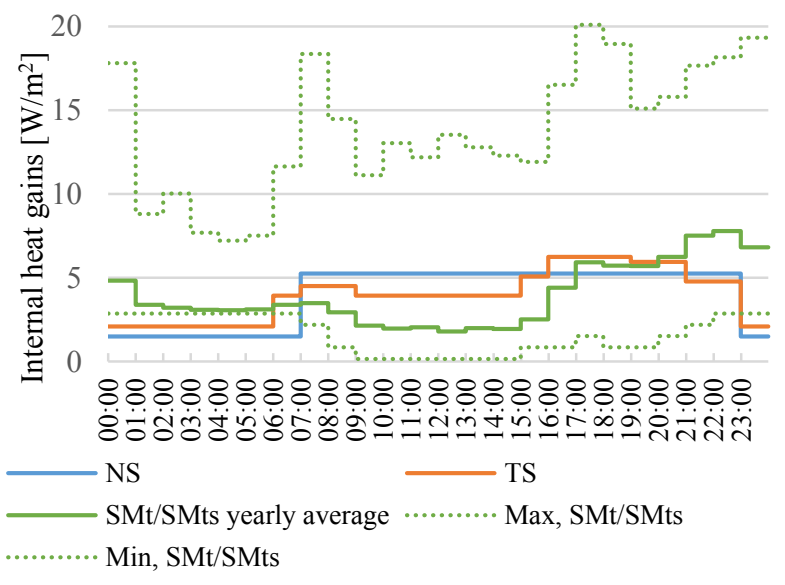

Fig. 2. Yearly-averaged internal heat gains from the four investigated profiles.

This occupancy profile does not contain as many fluctuations as the profiles for lighting and electric appliances. However, a separation is made between weekdays and weekends. In addition, variations in the occupancy have been considered for the summer, winter 
and spring/autumn months. The occupancy, appliance and lighting profiles are generated for a household of four persons. Finally, the stochastic profiles are scaled so that the yearly-averaged IHGs in $\mathrm{W} / \mathrm{m}^{2}$ is the same as in the two Norwegian standards (NS and TS). The daily IHG profiles are illustrated in Fig. 2, where the yearly average of the stochastic profile is shown along with the maximum and minimum values.

\subsection{Summary of simulation scenarios}

Table 3 summarizes the control scenarios investigated. All simulations are carried out with both thermostatic and P-control. To evaluate the influence of internal thermal zoning, the RBCs either impose the changes of the TSP to the bedrooms or not. This last scenario, here called "decoupled" bedrooms, applies a constant TSP in bedrooms, of either $16^{\circ} \mathrm{C}$ or $21^{\circ} \mathrm{C}$. The internal doors are always closed for all scenarios. Furthermore, the effects of overruling the SPCS during nighttime is evaluated, also in combination with decoupled bedrooms.

Table 3. Summary of control strategy scenarios: the flexibility is also evaluated with the bedrooms decoupled (bdc) from the control strategy with a constant TSP of $21^{\circ} \mathrm{C}$ or $16^{\circ} \mathrm{C}$; SPCS is also evaluated with no overruling at nighttime (nor).

\begin{tabular}{|c|c|c|}
\hline $\begin{array}{c}\text { Control } \\
\text { Strategies }\end{array}$ & $\begin{array}{c}\text { Overruling } \\
\text { nighttime }\end{array}$ & $\begin{array}{l}\text { Bedrooms } \\
\text { Decoupled }\end{array}$ \\
\hline OPCS & - & No \\
\hline $\mathrm{OPCS}_{\mathrm{bdc} 21}$ & - & Yes (TSP $\left.21^{\circ} \mathrm{C}\right)$ \\
\hline OPCS $_{\text {bdc } 16}$ & - & Yes (TSP $\left.16^{\circ} \mathrm{C}\right)$ \\
\hline SPCS & Yes & No \\
\hline $\mathrm{SPCS}_{\text {nor }}$ & No & No \\
\hline SPCS $_{\text {bdc } 21}$ & Yes & Yes (TSP $\left.21^{\circ} \mathrm{C}\right)$ \\
\hline $\mathrm{SPCS}_{\mathrm{bdc} 16}$ & Yes & Yes (TSP $\left.16^{\circ} \mathrm{C}\right)$ \\
\hline SPCS $_{\text {nor+bdc16 }}$ & No & Yes (TSP $\left.16^{\circ} \mathrm{C}\right)$ \\
\hline
\end{tabular}

To be able to evaluate the effects of the RBC strategies, each of the simulation scenarios is compared with a reference case with a constant TSP of $21{ }^{\circ} \mathrm{C}$. Each investigated scenario has its own reference case. The only difference between the investigated scenario and its respective reference case is the implementation of RBC strategy. This means that the effects of the RBC strategy are compared with a simulation of the same building type with the same radiator controller and IHG profile. For the OPCS $_{\text {bdc16 }}$ and $\mathrm{SPCS}_{\mathrm{bdc} 16}$, the reference case has a constant TSP of $16{ }^{\circ} \mathrm{C}$ in the bedrooms. In conclusion, there are separate reference simulations for the different building types, IHG profiles and radiator controls. Based on the performance of the respective reference simulation, the energy flexibility potential of each simulation case is here evaluated using a single KPI. The KPI, called $\mathrm{q}_{\mathrm{ph}}$, is the ratio between the energy use in peak hours for the simulation with a implemented control strategy $\left(\mathrm{Q}_{\mathrm{ph}, \mathrm{RBC}}\right)$ and the energy use in the peak hours with the reference simulation with constant TSP $\left(\mathrm{Q}_{\mathrm{ph}, \mathrm{ref}}\right)$. This KPI is defined by equation 1 :

$$
q_{p h}=\frac{Q_{p h, R B C}}{Q_{p h, r e f}}
$$

For clarity this means that a $\mathrm{q}_{\mathrm{ph}}$ of 1 means that no energy is shifted in the peak hours, i.e. the energy consumption in the peak hours is the same as the reference case without the implemented RBC. A low value for $\mathrm{q}_{\mathrm{ph}}$ indicates more energy shifted and a value of 0 means that the energy use is fully shifted away from peak hours.

\section{Results}

This section successively shows the effect of the radiator control type, the IHG profile and the temperature zoning on the flexibility potential.

\subsection{Controller type and internal heat gains}

Table 4 shows the relative change in energy use during the peak hours $\left(\mathrm{q}_{\mathrm{ph}}\right)$ with OPCS and SPCS for both controller types using $\mathrm{SM}_{\mathrm{ts}}$ IHGs. Both RBC strategies successfully shift energy and power use from the defined peak hours to off-peak hours. The share of shifted energy and power is much more significant for the $\mathrm{PH}$ buildings than the TB buildings. In PH buildings, the OPCS leads to zero energy and power consumption during the four defined peak hours of the day throughout the year.

Table 4 KPI for energy use during peak hours $\left(q_{p h}\right)$ with OPCS and SPCS: results are given for both proportional and thermostatic control and using $S M_{t s} I H G$ profile.

\begin{tabular}{lcccc}
\hline RBC & PHL & PHH & TBL & TBH \\
\hline \multicolumn{5}{c}{ Proportional control (PC) } \\
\hline OPCS & 0.000 & 0.000 & 0.139 & 0.078 \\
SPCS & 0.557 & 0.586 & 0.663 & 0.570 \\
\hline \multicolumn{5}{c}{ Thermostatic control (TC) } \\
\hline OPCS & 0.000 & 0.000 & 0.086 & 0.028 \\
SPCS & 0.525 & 0.582 & 0.629 & 0.515 \\
\hline
\end{tabular}

Fig. 3(a) shows the absolute change in yearly energy use during the peak hours compared to the reference cases, for the OPCS and SPCS and for the PHL and PHH. This is given for both radiator controls and all four IHG profiles. Stochastic profiles always result in the largest amount of energy shifted from peak hours, the $\mathrm{SM}_{\mathrm{ts}}$ is the profile with the highest amount of shifted energy. Furthermore, with stochastic IHG profiles the magnitude of energy shifted is relatively similar with thermostatic and proportional control. For standard static IHGs the magnitude of energy shifted is much more significant with proportional control. The same is illustrated for the TB buildings in Fig. 3(b). The magnitude of energy reduced during peak hours for these TB buildings is almost ten times higher than for the PH buildings. Unlike the PH buildings, the difference of energy shifted between the different control types and IHG profiles is limited.

The space-heating power given in Fig. 4(a) is the average of the 20 equivalent PHL buildings, but with different $\mathrm{SM}_{\mathrm{ts}}$ profiles. This is given for $22^{\text {nd }}$ January. The average spaceheating power is compared for the reference and the RBC, with thermostatic and proportional control. Fig. 4 shows that the aggregated space-heating power of a neighborhood is very similar with thermostatic control and with P-control. It is assumed that with more buildings with different $\mathrm{SM}_{\mathrm{ts}}$ IHG 
profiles, the results with the thermostatic controller would be smoother. The most significant difference with a thermostatic controller compared to the P-controller is the rebound peak with OPCS. The aggregation with a Pcontroller results in a more distinct rebound peak after the pre-defined peak hours. This is because in some of the building zones, especially the ones with floor heating (technical room, bathrooms), the air temperature will not drop below $20.5^{\circ} \mathrm{C}$ during the peak hours. If the temperature in these zones is between $20.5^{\circ} \mathrm{C}$ and $21^{\circ} \mathrm{C}$, the P-controller will start to operate while the thermostatic controller will wait until the temperature is below $20.5^{\circ} \mathrm{C}$. Therefore, the selection of the start and stop temperatures (or dead-band) of the thermostatic control or the constant of the P-control will also have an impact on the rebound effect.

(a)

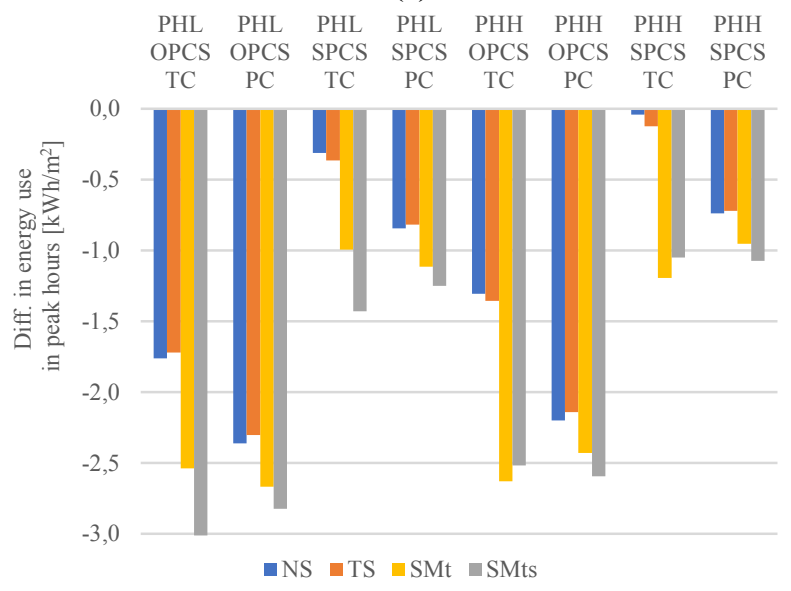

(b)

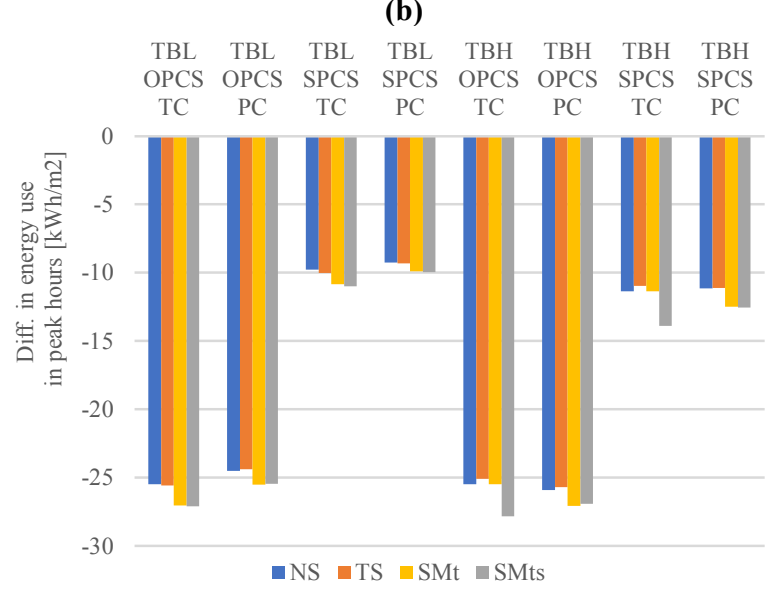

Fig. 3. Difference in annual specific energy use during peak hours between the reference and the OPCS or SPCS for (a) the $P H L$ and PHH and (b) for the TBL and TBH (for thermostatic control (TC) and proportional control (PC)).

The results for TBL, shown in Fig. 4(b), have the same trend as the PHL regarding the difference between radiator controls. However, unlike the PHL, the difference in rebound peak between the thermostatic and proportional controls is insignificant. As the temperature drop during peak hours is higher for the TB buildings, both the thermostatic and proportional controls will operate at full power right after the peak period and lead to the same magnitude of the rebound peak. Again, in terms of modeling, higher insulation levels require a more careful definition of the radiator control.

(a)

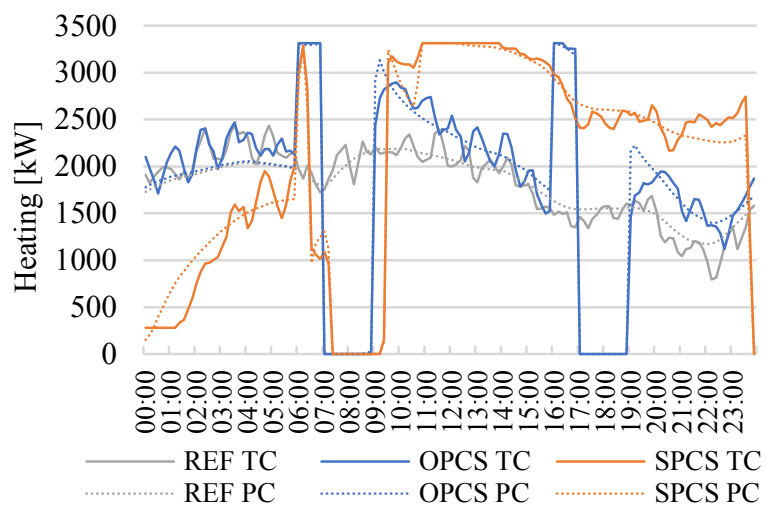

(b)

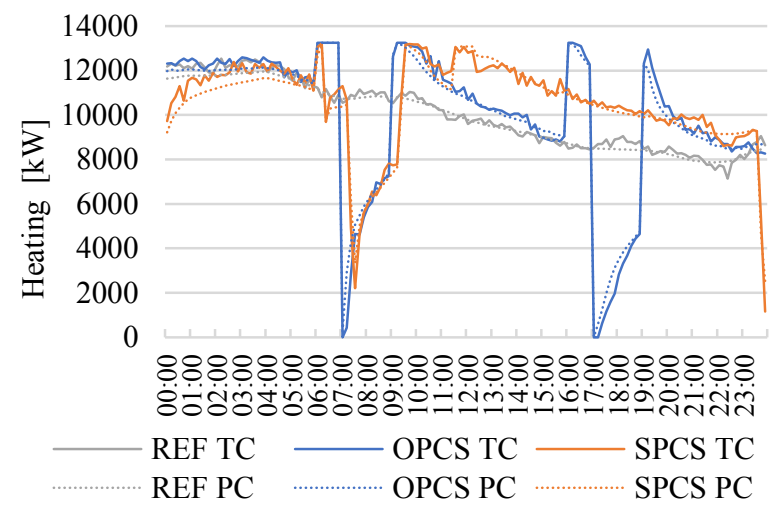

Fig. 4. Average space-heating power of (a) 20 PHL buildings and (b) 20 TBL buildings with different $S M_{\text {ts }}$ profiles for thermostatic and P control (given for one cold day for the reference case, OPCS and SPCS).

\subsection{Internal thermal zoning}

The effects of decoupling the bedrooms from the RBC strategies are investigated for the bedroom in the SouthEast corner of the building (bedroom SE). The operative temperature in bedroom SE is studied during nighttime during the heating season considering the $\mathrm{SM}_{\mathrm{ts}}$ profile. Based on simulations, the heating season is defined between October and April. Fig. 5(a) shows the time distribution of the operative temperature for the TB buildings with a constant bedroom TSP of $21^{\circ} \mathrm{C}$. A stable temperature for the reference case is obvious. OPCS and SPCS result in a temperature above $22{ }^{\circ} \mathrm{C}$ for almost $20 \%$ of the time. However, when the bedrooms are decoupled $\left(\mathrm{OPCS}_{\mathrm{bdc} 21}\right.$ and $\left.\mathrm{SPCS}_{\mathrm{bdc} 21}\right)$, the temperatures are similar to the reference cases. The bedroom temperature is not significantly affected by the two DSM controls whatever the construction mode, if decoupled.

It is difficult to achieve low bedroom temperatures in $\mathrm{PH}$ buildings due to the balanced mechanical ventilation with a centralized heat recovery, relatively low heat losses through the envelope and solar gains. Fig. 5(b) shows the percentage of time for different temperature intervals in bedroom SE in the PH during nighttime and the heating season. The analysis of the reference cases shows that the 
operative temperature is already above $22^{\circ} \mathrm{C}$ for about $30 \%$ of the time without any activation of the thermal mass using RBCs. The SPCS leads to a higher increase of bedroom temperatures than OPCS, especially for the lightweight $\mathrm{PH}$ building (PHL): the operative temperature is then above $22{ }^{\circ} \mathrm{C}$ for more than $50 \%$ of the night-time during the heating season. As for the TB buildings, decoupling the bedrooms from the RBC strategies has a positive effect on reducing the bedroom temperatures. The SPCS $\mathrm{Sdc}_{\mathrm{b} 21}$ results in a noticeable improvement: with this strategy, the share of time over $22{ }^{\circ} \mathrm{C}$ is reduced significantly. A difference can be noticed between the construction modes. Compared to PHL, PHH has less hours at high temperatures when RBC strategies are applied to bedrooms. However, the decoupling of the bedrooms is not as effective for PHH as for PHL. This is reasonable as internal walls of lightweight buildings are insulated, thus having a lower U-value than in heavyweight buildings. The heat transfer in internal constructions is significant in heavyweight buildings so that the bedroom temperature is influenced by temperature fluctuations generated by the RBCs in the neighboring rooms.

(a)

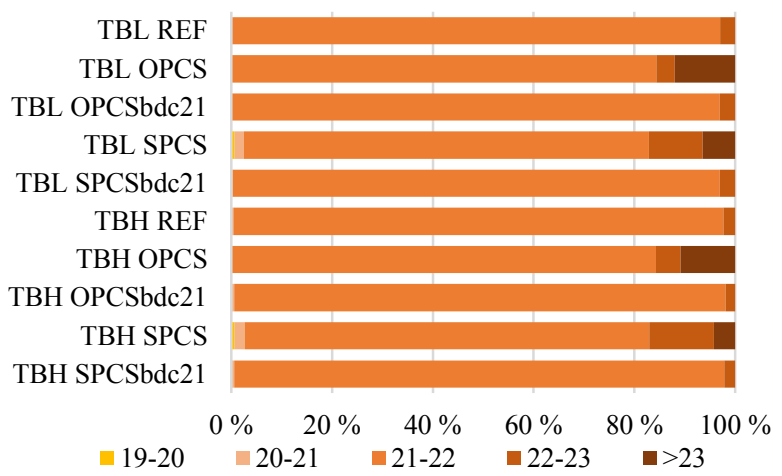

(b)

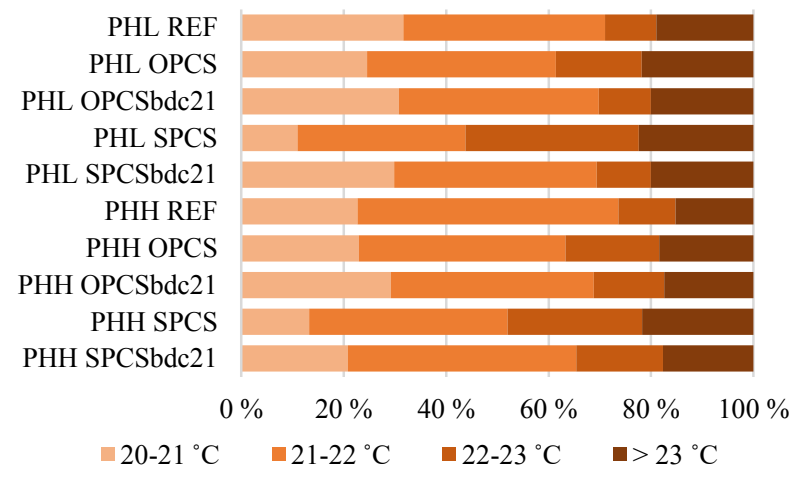

Fig. 5. Breakdown of the operative temperature into intervals in bedroom SE during night-time and the heating season: reference case TSP, the original $R B C s$ and the $R B C s$ with decoupled bedrooms with TSP of $21{ }^{\circ} \mathrm{C}$ for (a) TB and (b) PH.

Fig. 6 is similar to Fig. 5, but shows the cases for a TSP of $16{ }^{\circ} \mathrm{C}$ in the bedrooms. Regarding the TB buildings, Fig. 6(a) shows that these buildings. achieve temperatures close to this low TSP for most of the heating season TSP.

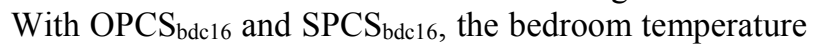
in TBL is below $17^{\circ} \mathrm{C}$ almost $100 \%$ of the time. For the reference control, the temperature is higher in the $\mathrm{TBH}$, but the temperature remains below $17{ }^{\circ} \mathrm{C}$ for $70 \%$ of the time. OPCS $S_{\text {bdc16 }}$ and SPCS $_{\text {bdc16 }}$ do not modify this trend. In addition, SPCS without overruling during nighttime

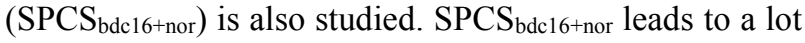
of hours with a TSP of $23{ }^{\circ} \mathrm{C}$ in the rest of the building (i.e. not bedrooms) but it only slightly increases the bedroom temperature. For the TB buildings, the thermal mass activation in the common rooms does not increase the resulting bedroom temperatures. Therefore, the risk to open windows to decrease bedroom temperatures is not expected to be higher with the thermal mass activation.

(a)

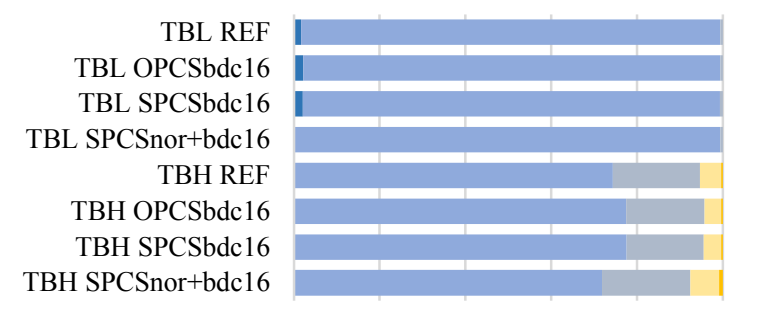

$\begin{array}{llllll}0 \% & 20 \% & 40 \% & 60 \% & 80 \% & 100 \%\end{array}$

$\square<15^{\circ} \mathrm{C} \square 15-16^{\circ} \mathrm{C} \square 16-17^{\circ} \mathrm{C} \square 17-18 \square 18-19 \square 19-20$

(b)

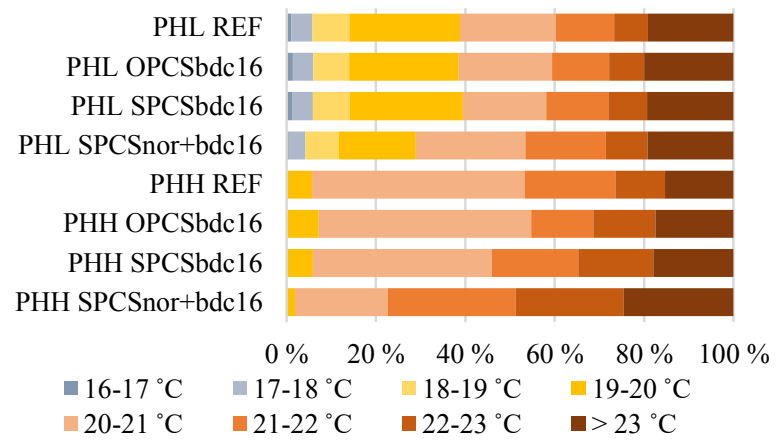

Fig. 6. Breakdown of the operative temperature into intervals in bedroom SE during night-time in the heating season: reference case TSP, the original RBCs and the RBCs with decoupled bedrooms with TSP of $16^{\circ} \mathrm{C}$ with and without overruling for (a) TB and (b) $P H$.

Fig. 6(b) shows the time distribution of the operative temperature for the $\mathrm{PH}$ buildings. The reference for these cases is taken with a constant TSP of $16{ }^{\circ} \mathrm{C}$ in the bedrooms and $21{ }^{\circ} \mathrm{C}$ in the rest of the zones. In general, the reduction of the TSP to $16^{\circ} \mathrm{C}$ in the bedrooms does not contribute to a reduction of the highest temperatures for the PH buildings. This indicates that the temperature of $23{ }^{\circ} \mathrm{C}$ is not due to the TSP, but rather due to internal and solar heat gains. With a TSP of $16{ }^{\circ} \mathrm{C}$, the bedroom radiators are off during the entire year for the PHH. Only the PHL achieves bedroom temperatures close to the TSP, leading to small space-heating needs for a low share of the time. One main reason for this, especially for the colder months, is that the ventilation supply air TSP is $20^{\circ} \mathrm{C}$ (which is a common set-point). Thus, even with no heat from local heating units, the heat from the supply air and other zones will keep bedrooms warm. The implementation of the RBCs leads to limited changes of the bedroom temperature except for the $\mathrm{SPCS}_{\mathrm{bdc} 16+\text { nor }}$ in the $\mathrm{PHH}$ building. Besides this single case, the 
temperature in bedrooms is not affected by the RBCs suggesting that the risk of window opening is not increased.

By decoupling the bedrooms from the RBC strategies, the amount of energy and power shifted is reduced, as the radiators in the bedrooms will operate with a constant TSP of $21{ }^{\circ} \mathrm{C}$ or $16^{\circ} \mathrm{C}$. The energy flexibility potential with the bedrooms decoupled from the $\mathrm{RBC}$ strategies is evaluated using the energy use during peak hours $\left(q_{p h}\right)$ for the reference case and for the RBC strategies. Again, $\mathrm{OPCS}_{\mathrm{bdc} 16}$ and $\mathrm{SPCS}_{\mathrm{bdc1} 16}$ are evaluated against a reference case with a constant TSP of $16^{\circ} \mathrm{C}$ in the bedrooms and 21 ${ }^{\circ} \mathrm{C}$ in the other zones. In general, the indicator $\mathrm{q}_{\mathrm{ph}}$ is higher when bedrooms are decoupled (bdc) from the RBC compared to the scenario with coupled bedrooms. This is illustrated in Fig. 7.

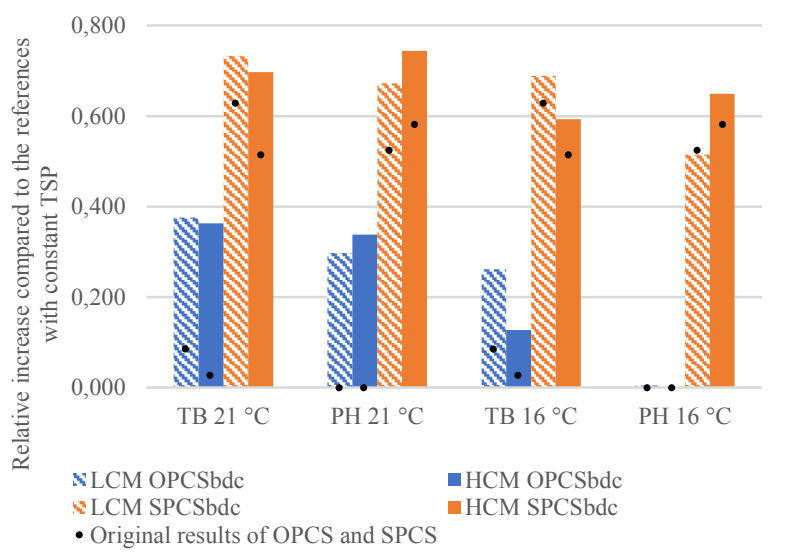

Fig. 7. Energy use relative to the respective reference case during peak hours with OPCSbdc21/bdc16 and SPCSbdc21/bdc16: original results of the OPCS and SPCS without decoupling are illustrated with black marks.

\section{Conclusions}

This work evaluated the energy flexibility that Norwegian residential buildings can provide to the electricity grid. This has been done using rule-based controls (RBC) that adjust the temperature set-point (TSP) of a direct electric space-heating system. Physical aspects which may influence the energy flexibility are investigated, including internal heat gains (IHG), the type of radiator control and the occupant preference for cold or warm bedrooms.

Two RBC strategies activating the building energy flexibility are applied: one with a pre-defined schedule (OPCS) that aims at reducing electricity use during peak hours and one that aims at decreasing energy costs using time-variable spot prices (SPCS). These RBCs have been evaluated using simulations for a detached house with two different insulation levels and two construction modes. The main focus was the load shifting away from peak hours (which is a main concern in Norway). Results showed that all building types have potential to shift their energy and power use. The buildings with a higher insulation level achieve a higher relative share of energy and power shifted. Although less insulated buildings have a lower relative peak shaving potential, the magnitude of the energy and power shifted is significantly higher.
With highly-insulated buildings, the largest potential for energy and power shifting was found for stochastic IHG profiles, which are assumed to be the most realistic representations of occupant behaviour. However, the influence of the internal gains on the energy shifted is small for the less-insulated buildings. This indicates that the flexibility potential using thermal mass can be dependent on the timing of the IHGs, especially in highlyinsulated buildings. Thus, modelling IHGs using standard fixed profiles may underestimate the load-shifting.

It was found that the type of radiator control has an impact on the energy and load shifting potential of highlyinsulated buildings, whereas this effect is almost negligible for low insulation levels. The two RBCs were also evaluated for 20 identical buildings but with different stochastic IHG profiles. Considering aggregated results, the performance of the thermostatic control converges to a proportional control. Proportional control can thus reasonably be used to evaluate the energy flexibility of several buildings. However, for highly-insulated buildings, the rebound peak right after the peak hours was found to be higher with proportional control compared to thermostatic control.

With low insulation levels, cold bedrooms can be easily created by applying a low temperature set-point in these rooms (e.g. $\sim 16{ }^{\circ} \mathrm{C}$ ). If the two RBCs are not applied to bedrooms (but only to the rest of the building), bedroom temperatures do not increase significantly. With high insulation levels including a centralized heat recovery of the ventilation air, it is intrinsically difficult to create cold bedrooms. Periods with moderate to high bedroom temperatures will be found systematically during the space-heating season (as long as bedroom windows are not open). If the two RBCs are not applied to bedrooms (but only to the rest of the building), they do not amplify this phenomenon. Consequently, these results suggest that the activation of the building thermal mass, if not applied in bedrooms, will not further increase the risk of window opening or user dissatisfaction in bedrooms. The window opening should be avoided as it would lead to a noticeable increase of the space-heating needs. In addition, the thermal mass activation without considering bedrooms leads to a moderate reduction of the load-shifting potential compared to the activation of the entire building.

As a general comment, higher insulation levels require more complexity for all the physical phenomena investigated (i.e. IHG definition, radiator control and temperature zoning). Results are relatively insensitive to this modelling complexity for low insulation levels. As most of the Norwegian building stock is composed of low-insulated buildings, this is an important conclusion.

\section{Acknowledgements}

The authors would like to acknowledge IEA EBC Annex 67 and the Norwegian Research Center on Zero Emission Neighborhoods in Smart Cities, ZEN, as this work has been carried out under these frameworks. The authors would like to thanks Dr. Igor Sartori (Senior Researcher at SINTEF Building and Infrastructure) for his explanations and support regarding stochastic internal heat gains. 


\section{References}

1. Norges vassdrags- og energidirektorat. $N y$ teknologi og forbrukerfleksibilitet. 2015 Updated: 04.05.2017 [cited 2018 25.01]; Available from: https://www.nve.no/elmarkedstilsynet-markedog-monopol/sluttbrukermarkedet/ny-teknologiog-forbrukerfleksibilitet/.

2. Langseth, B., I.H. Magnussen, and D. Spilde, Energibruksrapporten 2013, NVE, Editor. 2014.

3. Aduda, K.O., et al., Demand side flexibility: Potentials and building performance implications. Sustainable Cities and Society, 2016. 22: p. 146-163.

4. Clauß, J., et al., Control strategies for building energy systems to unlock demand side flexibility - A review, in 12th International Conference of IBPSA. 2017: San Francisco, US.

5. Jensen, S.Ø., et al., IEA EBC Annex 67 Energy Flexible Buildings. Energy \& Buildings, 2017. 155: p. 25-34.

6. Reynders, G., et al., Potential of structural thermal mass for demand-side management in dwellings. Building and Environment, 2013. 64: p. 187-199.

7. Le Dréau, J. and P. Heiselberg, Energy flexibility of residential buildings using short term heat storage in the thermal mass. Energy, 2016. 111: p. 991-1002.

8. Reynders, G., J. Diriken, and D. Saelens, $A$ Generic Quantification Method for the Active Demand Response Potential of Structural Storage in Buildings, in 14th Conference of International Building Performance Simulation Association. 2015.

9. Clauß, J., et al. Investigations of Different Control Strategies for Heat Pump Systems in a Residential nZEB in the Nordic Climate. in 12th IEA Heat Pump Conference. 2017. Rotterdam, Netherlands.

10. Dar, U.I., et al., Advanced control of heat pumps for improved flexibility of Net-ZEB towards the grid. Energy \& Buildings, 2014. 69: p. 74-84.

11. Deru, M. and P. Torcellini, Performance Metrics Research Project - Final Report. 2005.

12. Yan, D., et al., IEA EBC Annex 66: Definition and simulation of occupant behavior in buildings. Energy and Buildings, 2017. 156: p. 258-270.

13. Richardson, I., et al., Domestic electricity use: $A$ high-resolution energy demand model. Energy and Buildings, 2010. 42(10): p. 1878-1887.

14. Berge, M., J. Thomsen, and H.M. Mathisen, The need for temperature zoning in highperformance residential buildings. Journal of Housing and the Built Environment, 2017. 32(2): p. 211-230.
15. Georges, L., et al., Simplified Space-heating Distribution Using Radiators in Super-insulated Apartment Buildings. Energy Procedia, 2016. 96: p. 455-466.

16. Thomsen, J., et al., Evaluering av boliger med lavt energibehov (EBLE) (Evaluation of housing with low energy needs). 2017.

17. Georges, L., et al., Evaluation of Simplified Space-Heating Hydronic Distribution for Norwegian Passive Houses. 2017, SINTEF akademisk forlag.

18. Georges, L., F. Håheim, and M.J. Alonso, Simplified Space-Heating Distribution using Radiators in Super-Insulated Terraced Houses. Energy Procedia, 2017. 132(C): p. 604-609.

19. Thibault, Q.P., O. Joana, and S. Jaume, Impact of Demand-Side Management on Thermal Comfort and Energy Costs in a Residential nZEB. Buildings, 2017. 7(2): p. 37.

20. Arteconi, A., et al., Active demand response with electric heating systems: Impact of market penetration. Applied Energy, 2016. 177(C): p. 636-648.

21. Brattebø, H., et al., Fremtidig utvikling $i$ energiforbruk og CO2-utslipp for Norges boligmasse. 2016.

22. Ericson, T., et al., Varmepumper $i$ energisystemet. 2016, NVE.

23. Standard Norge, NS3700:2013 Criteria for passive houses and low energy buildings, Residential buildings. 2013.

24. Brattebø, H., et al., Typologier for norske boligbygg - Eksempler på tiltak for energieffektivisering. 2016.

25. Direktoratet for byggkvalitet, Technical Building Works Regulations - TEK17. 2017.

26. Benjamin Donald Smith, et al., Nordic Energy Technology Perspectives 2016: Cities, flexibility and pathways to carbon-neutrality. 2016: International Energy Agency (IEA).

27. Nord Pool AS. Day-ahead prices. 2016 [cited 2018 05.02]; Available from: https:/www.nordpoolgroup.com/Marketdata1/Dayahead/AreaPrices/ALL1/Hourly/? view=table.

28. Rangøy, E., Master Thesis: Validation of user profiles for building energy simulations. 2013, Norwegian University of Science and Technology. 